\title{
Urinary lactate to creatinine ratio in neonates with perinatal asphyxia and its correlation with severity of hypoxic ischemic encephalopathy
}

\author{
Kankane $\mathbf{A}^{1}$, Kankane $\mathbf{A}^{2}$, Tripathi $\mathbf{P R}^{3}$ \\ ${ }^{1}$ Dr. Aradhana Kankane, Associate Professor, Department of Pediatrics, Maharani Laxmibai Medical College, Jhansi, \\ Uttar Pradesh, India, ${ }^{2}$ Dr Arvind Kankane, Assistant Professor, Department of Neurology, Maharani Laxmibai Medical \\ College, Jhansi, Uttar Pradesh, India, ${ }^{3}$ Dr. Parijat Ram Tripathi, Senior Resident, Department of Pediatrics, Maharani \\ Laxmibai Medical College Jhansi Uttar Pradesh, India
}

Address for Correspondence:- Dr Aradhana Kankane, Associate Professor, Department of Pediatrics, Maharani Laxmibai Medical College, Jhansi,Uttar Pradesh, India, E- mail:- draradhana_2002@rediffmail.com

\begin{abstract}
Background: Neonates with perinatal asphyxia are prone to development of hypoxic ischemic-encephalopahty (HIE). There are no reliable methods for prediction of HIE in these neonates. Objectives: To determine urinary lactate to creatinine ratio in neonates with perinatal asphyxia and its correlation with severity of hypoxic ischemic encephalopathy. Material and Methods: A prospective study was carried out at neonatal intensive care unit (NICU) at Department of Pediatrics, MLB Medical College Jhansi. 50 neonates born at $>36$ weeks gestation with perinatal asphyxia, admitted in neonatal intensive care unit were taken as cases and 50 normal newborns with gestational age $>36$ week included as control. We measured the ratio of lactate to creatinine in urine sample by colometric technique within $24 \mathrm{hr}$ after birth both in cases and controls. All newborns were followed for 7 days during their stay in hospital for development of HIE. The results were correlated with the subsequent presence or absence of HIE. Results: The study revealed that mean urinary lactate to creatinine ratio during first 24 hours of life was higher in asphyxiated neonates than control $\operatorname{group}(5.35 \pm 4.59$ vs $0.18 \pm .07)$, the difference was found to be statistically highly significant $(\mathrm{z}=7.693 ; \mathrm{p}=<0.0001)$. The grade of HIE correlated with the greater urinary lactate to creatinine ratio among cases and was significant $(\mathrm{p}=<0.0001)$. Conclusion: The urinary lactate to creatinine (Urinary L/C) ratio in newborn infants with asphyxia is significantly increased early in course of the disease which can be used as useful parameter for predicting the development of hypoxic ischemic encephalopathy.
\end{abstract}

Key words: Hypoxic ischemic encephalopathy, Neonate, Urinary lactate to creatinine ratio.

\section{Introduction}

Perinatal asphyxia is one of the most important causes of neonatal mortality and subsequent neurological disability among the infants who survive [1-3]. It occurs in 2.9 to 9 per 1000 term newborns. Neurological sequels are present in $25 \%$ to $28 \%$ of the affected infants [4]. The World Health Organization reports that approximately 1 million children worldwide die due to birth asphyxia, and about the same number may survive with significant long-term neurological disability [5]. It is important to identify infants at high risk for hypoxic ischemic encephalopathy in order to provide them proper treatment soon after birth $[6,7]$. However, most newborns with perinatal asphyxia have unpredictable

Manuscript received: $2^{\text {nd }}$ Feb 2016

Reviewed: $9^{\text {th }}$ Feb 2016

Author Corrected; $18^{\text {th }}$ Feb 2016

Accepted for Publication: $29^{\text {th }}$ Feb 2016 course $[2,3,7]$. Measurements of lactate dehydrogenase, hydroxybutyrate dehydrogenase, neuron-specific enolase, glial fibrillary acidic protein, brain-specific creatine kinase, glutamate, and interleukin- 6 in serum or cerebrospinal fluid are of some value as markers of hypoxic-ischemic encephalopathy $[3,8,9]$ but samples of cerebrospinal fluid are rarely obtained from infants with no clinical signs of encephalopathy and are dangerous to obtain from infants with evidence of increased intracranial pressure.

Severe tissue hypoxia causes accumulation of intermediary metabolites which are excreted by the kidneys [10]. Lactate is produced by anaerobic metabolism during an asphyxial insult and continues to be excreted in urine for long time [11-14]. Because 
lactate is in part excreted through the kidney, measurement of urinary lactate may also reflect the blood lactate level and the degree of metabolic derangement as a result of hypoxia and ischemia [15]. Creatinine excretion is dependent upon glomerular filtration and is reduced in asphyxia [10], whereas lactate is cleared partly by hepatic and renal metabolism and partly by tubular secretion [15] using high capacity $\mathrm{H}+$ /monocarboxylate [16] cotransporter operative even in shock [14] and its excretion is reflective of blood levels rather than renal status. Babies continue to excrete lactate but creatinine excretion is reduced. Thus the ratios increase accordingly [17].

In present study we measured urinary lactate to creatinine ratio by colorimetric assay for early identification of infants in whom hypoxic ischemic encephalopathy is likely to develop.

\section{Material \& Methods}

The study conducted in the Neonatology department of tertiary care centre of Jhansi. The period of study extended from December 2014 to September 2015. All newborns (both inborn and outborn babies) with gestational age $>36$ weeks with perinatal asphyxia were included in study.

Inborn babies were included in study group if they were satisfied all the following criteria.

1. Presence of intrapartum fetal distress with or without the presence of meconium staining of amniotic fluid.

2. An apgar score $<5$ at 5 minutes of birth

3. Need for immediate neonatal resuscitation with ventilation by bag and mask or via an endotracheal tube for more than one minute.

Out born babies were included in study group if they were satisfied all the following criteria.

1. Failure to cry after birth.

2. Needed assistance for breathing soon after birth.

3. Neurological picture compatible with hypoxic ischemic encephalopathy with no alternative diagnosis.

Babies were excluded from study if they had major congenital malformation, suspected of congenital infections, suffering from anuria or born to mothers having hypertension, diabetes mellitus, toxaemia of pregnancy or receiving general anaesthesia, pethidine and other drugs likely to cause depression in babies.
Only inborn babies were enrolled as control and comprised of newborn babies born after an uncomplicated pregnancy of $>36$ weeks, having an apgar score $>7$ at 5 minutes of birth, no signs of asphyxia and a normal course during the first week of life. The infants in both groups were examined daily during the first week after birth by a single examiner who did not know the results of the urinary testing. After taking informed consent from parents, detail history regarding maternal age, parity, gravidity, acute or chronic medical illness, mode of delivery, prolonged labour, presence of neonatal cyanosis and/or bradycardia or delayed first cry was taken. Clinical examination including Apgar score, vital signs and full neurological examination was done. Hypoxic-ischemic encephalopathy was classified as mild, moderate, or severe on the basis of the staging system described by Sarnat and Sarnat [18]. This system assesses the infant's level of consciousness, muscle tone, cranial nerves, primitive reflexes, spontaneous motor activity, autonomic function and seizures. Routine laboratory investigations including cord blood gases, complete blood count, C-reactive protein and liver and kidney functions tests were done.

Urinary lactate to creatinine (urinary $\mathrm{L} / \mathrm{C}$ ) ratio was measured by collecting spot urine samples within first 24 hours of life both from the control and study group using sterile bags attached to the perineum. Urine was centrifuged and analysed in the hospital laboratory immediately. Both urinary lactate (K627-100 D-lactate Colorimetric Assay Kit Biovision) and creatinine were tested by conventional enzymatic method on colorimeter. The oxidase enzyme in the kit converts lactate to pyruvic acid and hydrogen peroxide, which results in oxidative conversion of chromogen to produce a colored dye with absorption maximum at 450 $\mathrm{nm}$, the amount of which is directly proportional to the amount of lactate in the sample. Lactate levels in urine by conventional enzymatic methods are comparable to levels by proton NMR spectroscopy of urine [19] and that two methods can be used interchangeably. Creatinine in urine was measured by the concentration of a yellow orange colored dye formed from the reaction with Picric acid under alkaline conditions, which had its absorption maximum at $500 \mathrm{~nm}$. Mean of two groups were compared using student " $t$ " test. Data were tabulated and statistically analyzed with the Statistical Package for Social Sciences (SPPS) version 16. P-values less than 0.05 were considered significant. 


\section{Results}

Birth weight, gestational age, and sex were similar among the normal infants and the infants with asphyxia that developed hypoxic- ischemic encephalopathy (Table 1). The disease was judged to be mild (HIE 1) in 18, moderate (HIE 2) in 19, and severe (HIE 3) in 13 patients. The mean ratio of Urinary L/C in urine within 24 hours after birth was $5.35 \pm 4.59$ in the infants who subsequently developed hypoxic-ischemic encephalopathy which is about 30 times as high as the ratio in normal infants $(0.18 \pm 0.07, \mathrm{P}<0.0001)$ (Table 2$)$. There was a significant trend for the ratio to increase with the severity of the hypoxic- ischemic encephalopathy in 24 hours: $0.94 \pm 0.17$ in the infants with mild encephalopathy, $4.68 \pm 0.53$ in those with moderate encephalopathy, and $11.86 \pm 2.5$ in those with severe encephalopathy. Further, Urinary $\mathrm{L} / \mathrm{C}$ ratio of control group was compared with Urinary L/C ratio of cases with HIE 1, HIE 2 and HIE 3 respectively and the difference was found to be highly significant $(\mathrm{p}<0.0001)$ (Table3). Urinary lactate to creatinine ratio showed linear correlation with severity of $\operatorname{HIE}(r=0.917$; $\mathrm{p}<0.001)$ (Figure 1$)$.

Table-1: Comparison between characteristic of cases (asphyxial neonates) and controls(normal neonates)

\begin{tabular}{|l|l|l|l|}
\hline Characters & Case $\mathbf{n = 5 0}$ & Control $\mathbf{n = 5 0}$ & P value \\
\hline $\begin{array}{l}\text { Birth weight }(\mathrm{kg}) \\
(\text { Mean } \pm \text { SD) }\end{array}$ & $2.51 \pm 0.36$ & $2.58 \pm 0.33$ & $\begin{array}{c}0.3133 \\
\text { Insignificant }\end{array}$ \\
\hline $\begin{array}{l}\text { Mode of delivery } \\
\text { Vaginal }\end{array}$ & 31 & 22 & 0.1085 \\
Caesarean & 19 & 28 & Insignificant \\
\hline Gender distribution & 31 & 32 & 1.000 \\
Male & 19 & 18 & Insignificant \\
Female & $38.3 \pm 1.13$ & $38.15 \pm 1.23$ & 0.5269 \\
\hline Gestational age (weeks) & & & Insignificant \\
X \pm SD & $(37-41)$ & $(37-41)$ & \\
Range & & & \\
\hline
\end{tabular}

Table-2: Comparison of means of different parameters between the cases and controls

\begin{tabular}{|l|l|l|l|l|}
\hline Parameters & $\begin{array}{l}\text { Cases } \\
\text { Mean } \pm \text { SD } \\
(\mathbf{n = 5 0 )}\end{array}$ & $\begin{array}{l}\text { Controls } \\
\text { Mean } \pm \text { SD } \\
(\mathbf{n = 5 0 )}\end{array}$ & $\mathbf{Z}$ & $\mathbf{P}$ \\
\hline Urinary lactate (mg/dl) & $147.60 \pm 93.94$ & $23.06 \pm 10.86$ & 9.3124 & $\begin{array}{l}<0.0001 \\
\text { Highly } \\
\text { significant }\end{array}$ \\
\hline $\begin{array}{l}\text { Urinary creatinine } \\
(\mathrm{mg} / \mathrm{dl})\end{array}$ & $58.90 \pm 108.32$ & $126.30 \pm 18.68$ & 4.3358 & $\begin{array}{l}<0.0001 \\
\text { Highly } \\
\text { significant }\end{array}$ \\
\hline $\begin{array}{l}\text { Urinary lactate to } \\
\text { creatinine ratio }\end{array}$ & $5.35 \pm 4.59$ & $0.18 \pm .07$ & 7.9630 & $\begin{array}{l}<0.0001 \\
\text { Highly } \\
\text { significant }\end{array}$ \\
\hline
\end{tabular}

Table-3: Comparison of different parameters in different HIE grades and controls

\begin{tabular}{|c|c|c|c|c|c|c|c|}
\hline \multirow{2}{*}{ Parameter } & \multirow{2}{*}{ HIE 1} & \multirow{2}{*}{ HIE 2} & \multirow{2}{*}{ HIE 3} & \multirow{2}{*}{ Controls } & \multicolumn{3}{|l|}{ Significance } \\
\hline & & & & & $\begin{array}{l}\text { Control vs } \\
\text { HIE } 1\end{array}$ & $\begin{array}{l}\text { Control vs } \\
\text { HIE } 2\end{array}$ & $\begin{array}{l}\text { Control vs } \\
\text { HIE } 3\end{array}$ \\
\hline $\begin{array}{l}\text { Ula/Cr ratio } \\
(\text { mean } \pm \text { SD) }\end{array}$ & $\begin{array}{l}0.94177 \\
\pm 0.16614\end{array}$ & $\begin{array}{l}4.67556 \\
\pm 0.52519\end{array}$ & $\begin{array}{l}11.8593 \\
\pm 2.4585\end{array}$ & $\begin{array}{l}0.1804 \\
\pm 0.0749\end{array}$ & $\begin{array}{l}26.0861 \\
\mathrm{P}=<0.0001 \\
\text { Highly } \\
\text { significant }\end{array}$ & $\begin{array}{l}59.6438 \\
\mathrm{P}=<0.0001 \\
\text { Highly } \\
\text { significant }\end{array}$ & $\begin{array}{l}34.337 \\
\mathrm{P}=<0.0001 \\
\text { Highly } \\
\text { significant }\end{array}$ \\
\hline
\end{tabular}




\section{ULCR}

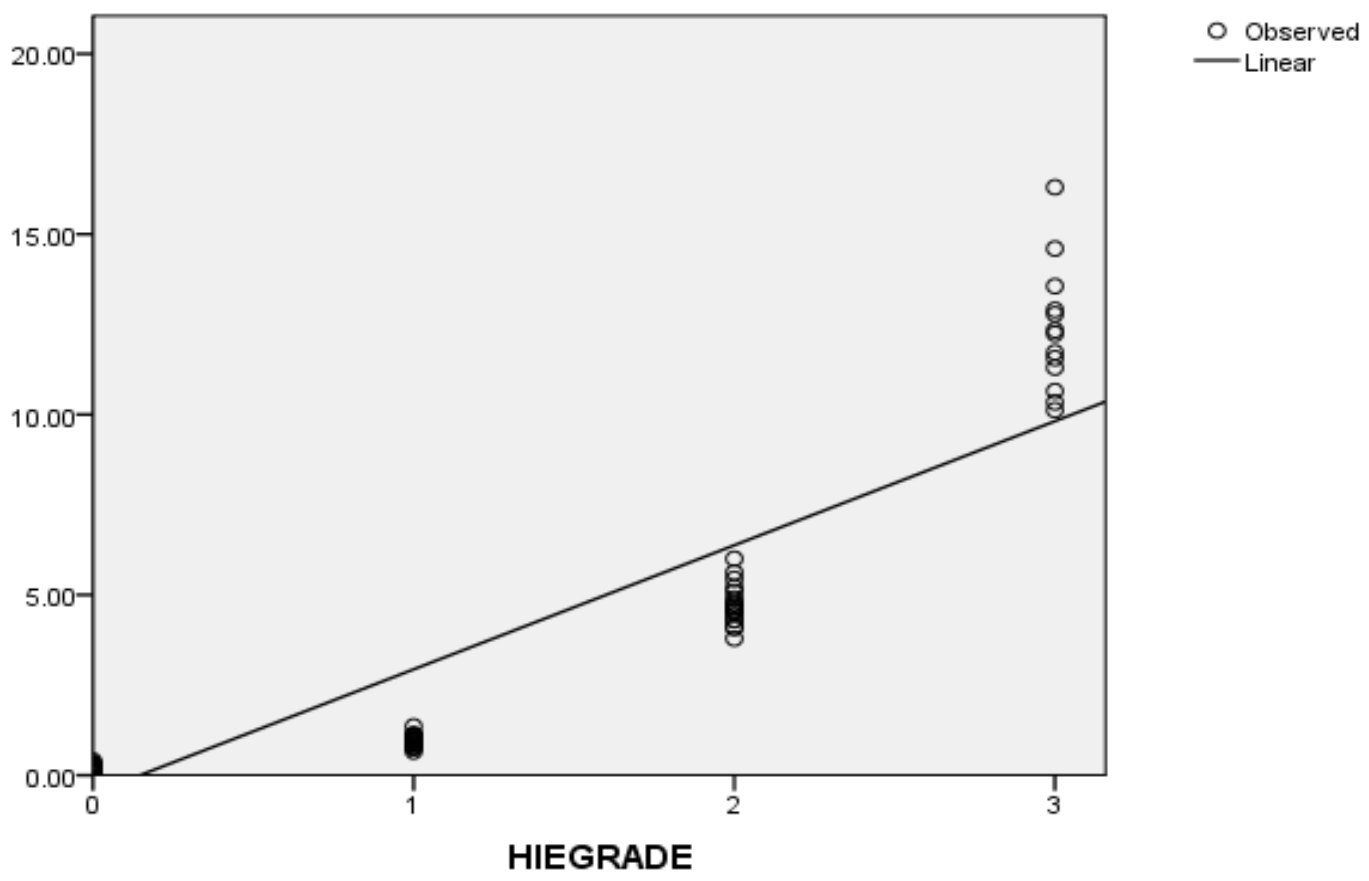

Figure-1: Linear regression curve illustratnig the correlation between HIE GRADE and urinary lactate to creatinine ratio

\section{Discussion}

In our study, the newborn infants with asphyxia were examined before hypoxic-ischemic encephalopathy developed. We selected 50 neonates with asphyxia admitted to our centre and 50 normal neonates. Within twenty four hours after birth, urinary $\mathrm{L} / \mathrm{C}$ ratios were much higher in the infants that developed hypoxicischemic encephalopathy. The ratio also increased as the hypoxic-ischemic encephalopathy worsened. These results suggest that the urinary $\mathrm{L} / \mathrm{C}$ ratio within twenty four hours after birth is related to the occurrence and degree of hypoxic-ischemic encephalopathy. We had chosen 24 hour period because some newborn presented late and some not passed urine in first 6 hour. Urinary $\mathrm{L} / \mathrm{C}$ ratio may reflect the general metabolic conditions of the perinatal hypoxia and reperfusion damage. Urinary lactate and creatinine estimations require only very simple instruments like photoelectric colorimeter or semi-autoanalyzer, simple reagents and simple techniques and can be acquired at low costs.

In present study, urinary $\mathrm{L} / \mathrm{C}$ ratio was found to be 30 times higher in babies with HIE compared to normal babies i.e. $5.35 \pm 4.59$ in cases, as against $0.18 \pm 0.07$ in control group (Table 2).Urinary $\mathrm{L} / \mathrm{C}$ ratio amongst HIE 1 babies was $0.94 \pm 0.17$, in HIE 2 it was $4.68 \pm 0.53$ while amongst HIE 3 babies it was $11.86 \pm 2.46$ (Table 3 ). Every newborn with ratio $>6.7$ developed severe encephalopathy and $84.6 \%$ of them died during course of treatment. Ghotbi and Najibi (2010) reported that $\mathrm{L} / \mathrm{C}$ ratio was $3.3 \pm 2$ among asphyxiated neonates in the first six hours after birth who subsequently developed HIE, which was 11 folds greater than in normal neonates $(0.3 \pm 0.08, \mathrm{P}=0.0001)$. This ratio decreased to $(1.5 \pm 0.55)$ for asphyxiated cases in the first 24 hours after birth, which was 5 folds greater than in control group $(\mathrm{P}=0.0001)[21]$. Ojha et al (2006) showed that urinary $\mathrm{L} / \mathrm{C}$ ratios are much higher in babies with thin meconium, and meconium staining was indicator of perinatal asphyxia of newborns [22]. Haung et al (1999) found that within six hours after birth, the mean $( \pm \mathrm{SD})$ ratio of urinary $\mathrm{L} / \mathrm{C}$ was $16.75 \pm 27.38$ in the infants who subsequently had hypoxic-ischemic encephalopathy, as compared with $(0.09 \pm 0.02)$ in the normal infants $(\mathrm{P}<0.001)$ and concluded that the measurement of 
urinary $\mathrm{L} / \mathrm{C}$ ratio within the first six hours after birth may identify infants at high risk for developing hypoxic ischemic encephalopathy. They also found that there was an insignificant trend for the ratio to increase with the severity of the hypoxic-ischemic encephalopathy [10]. But in our study we found a significant trend for ratio to increase $(\mathrm{r}=0.917 ; \mathrm{p}<0.001)$. As a limitation of our study we could not follow patients after discharge from NICU and compare growth and development in the two groups for determination of relationship between urinary $\mathrm{L} / \mathrm{C}$ ratio and their growth and development.

\section{Conclusion}

Urinary $\mathrm{L} / \mathrm{C}$ ratio was high in babies with perinatal asphyxia who subsequently developed HIE than normal babies. It also correlates with the severity of hypoxic ischemic encephalopathy. So urinary lactate to creatinine ratio can be used as early, simple, quick and non-invasive biochemical marker and a tool for predicting the development of hypoxic ischemic encephalopathy, and determine its severity. The ratio may therefore be useful in identifying infants most likely to benefit from intervention.

\section{Funding: Nill, Conflict of Interest: None \\ Permission of IRB: Yes}

\section{References}

1. Synder EY, Aurora S. Perinatal asphyxia. In: Cloherty JP, Eichenwald EC, Stark AR (eds). Manual of Neonatal Care. 5th edition. Lippincott Williams \& Wilkin. Philadelphia; 2004: 536-55.

2. Perlman JM, Risser R. Can asphyxiated infants at risk for neonatal seizures be rapidly identified by current high-risk markers? Pediatrics. 1996 Apr;97(4):456-62.

3. Volpe JJ, editor. Neurology of the Newborn. 5th ed. Philadelphia: $\quad$ Elsevier $\quad$ Science; 2008. Hypoxic-Ischemic Encephalopathy: Biochemical and Physiological Aspects; pp.221-372.

4. Zanardo V, Demi M, Padovani E. [Hypoxicischemic brain damage in the newborn] Pediatr Med Chir. 1997 Jan-Feb;19(1):1-2.

5. Martínez-Pérez B, de la Torre-Díez I, LópezCoronado M. Mobile health applications for the most prevalent conditions by the World Health Organization: review and analysis. J Med Internet Res. 2013 Jun 14;15(6):e120. doi: 10.2196/jmir.2600.

6. Vannucci RC, Perlman JM. Interventions for perinatal hypoxic-ischemic encephalopathy. Pediatrics. 1997 Dec;100(6):1004-14.

7. Johnston MV. Selective vulnerability in the neonatal brain. Ann Neurol. 1998 Aug;44(2):155-6.

8. Thornberg E, Thiringer K, Hagberg H, Kjellmer I. Neuron specific enolase in asphyxiated newborns: association with encephalopathy and cerebral function monitor trace. Arch Dis Child Fetal Neonatal Ed. 1995 Jan;72(1):F39-42.

9. Martín-Ancel A, García-Alix A, Pascual-Salcedo D, Cabañas F, Valcarce M, Quero J. Interleukin-6 in the cerebrospinal fluid after perinatal asphyxia is related to early and late neurological manifestations. Pediatrics. 1997 Nov;100(5):789-94.

10. Huang CC, Wang ST, Chang YC, Lin KP, Wu PL. Measurement of the urinary lactate:creatinine ratio for the early identification of newborn infants at risk for hypoxic-ischemic encephalopathy. N Engl J Med. 1999 Jul 29;341(5):328-35.

11. Perlman JM, Tack ED. Renal injury in the asphyxiated newborn infant: relationship to neurologic outcome. J Pediatr. 1988 Nov;113(5):875-9.

12. da Silva S, Hennebert N, Denis R, Wayenberg JL. Clinical value of a single postnatal lactate measurement after intrapartum asphyxia. Acta Paediatr. 2000 Mar;89(3):320-3.

13. Leth H, Toft PB, Peitersen B, Lou HC, Henriksen O. Use of brain lactate levels to predict outcome after perinatal asphyxia. Acta Paediatr. 1996 Jul;85(7):85964.

14.Nordström L, Chua S, Roy A, Naka K, Persson B, Arulkumaran S. Lactate, lactate/pyruvate ratio and catecholamine interrelations in cord blood at delivery in complicated pregnancies. Early Hum Dev. 1998 Aug 28;52(1):87-94.

15. Hanrahan JD, Cox IJ, Edwards AD, Cowan FM, Sargentoni J, Bell JD, Bryant DJ, Rutherford MA, Azzopardi D. Persistent increases in cerebral lactate concentration after birth asphyxia. Pediatr Res. 1998 Sep;44(3):304-11 
16. Bellomo R. Bench-to-bedside review: lactate and the kidney. Crit Care. 2002 Aug;6(4):322-6. Epub 2002 Jun 7.

17. Poole RC, Halestrap AP. Transport of lactate and other monocarboxylates across mammalian plasma membranes. Am J Physiol. 1993 Apr;264(4 Pt 1):C76182.

18. Ikeda T, Murata Y, Quilligan EJ, Parer JT, Murayama T, Koono M: Histologic and biochemical study of the brain, heart, kidney, and liver in asphyxia caused by occlusion of the umbilical cord in near-term fetal lambs.Am J Obstet Gynecol 2000, 182(2):449-57.

19. Sarnat HB, Sarnat MS. Neonatal encephalopathy following fetal distress. A clinical and electroencephalographic study. Arch Neurol. 1976 Oct;33(10):696-705.
20. Zuppi C, Messana I, Forni F, Rossi C, Pennacchietti L, Ferrari F, Giardina B. 1H NMR spectra of normal urines: reference ranges of the major metabolites. Clin Chim Acta. 1997 Sep 8;265(1):85-97.

21. Ghotbi N, Najibi B. Measurement of the urinary lactate/creatinine ratio for early diagnosis of the hypoxic-ischemic encephalopathy in newborns. Iran J Pediatr. 2010 Mar;20(1):35-40

22. Ojha RK, Singh SK, Batra S, Sreenivas V, Puliyel JM. Lactate: creatinine ratio in babies with thin meconium staining of amniotic fluid. BMC Pediatr. 2006 Apr 20;6:13.

\section{How to cite this article?}

Kankane A, Kankane A, Tripathi PR, Urinary lactate to creatinine ratio in neonates with perinatal asphyxia and its correlation with severity of hypoxic ischemic encephalopathy:Int J Pediatr Res 2016;3(3):162-167. doi:10.17511/ijpr.2016.i03.05. 